\title{
Multi-objective analysis of Polish domestic power system development from point of view of unmanned factories. A cybernetic issue
}

\author{
JERZY TCHÓRZEWSKI \\ Institute of Computer Science \\ Siedlce University of Natural Sciences and Humanities \\ 3 Maja 54, 08-110 Siedlce, Poland \\ e-mail: jtchorzewski@interia.pl,Jerzy.Tchorzewski@uph.edu.pl
}

(Received: 12.11.2015, Revised: 16.03.2016)

\begin{abstract}
The paper contains selected results of research on the Domestic Power System (DPS) as an unmanned factory. Models of the DPS system of the MISO type, obtained as a result of identification for 14 inputs and 4 outputs were presented. Particular attention was given to the identification and the assessment of the DPS development based on the systems and control theory. The obtained models of the DPS development were analyzed and discussed. The studies were obtained model of the development of the DPS, and on the basis of is knowledge of the structural and parametrical changes of system development. The model can be used to analyze the design and development of the system from the point of view of the growth of internal organization system and the transition to higher levels of control.
\end{abstract}

Key words: development model, identification process, MATLAB and Simulink environment, multi-parameters analyze, power system modeling, unmanned factory

\section{Introduction}

There are different methods of research such as: forecast [11], planning [1,12] or programming [7-9] models, which are obtained as a result of using one scenario algorithm of the Domestic Power System and in this paper they were used as a basis for finding new states of development. So far there have been no research results on the systems and control theory using multi-scenario algorithms [12-13]. In this respect, this work contributes to the theory and practice of studies on the DPS ${ }^{1}$ development in regards to design work from the point of view of unmanned factories ${ }^{2}$. It is concerned with searching for the degree of increase of the

${ }^{1}$ DPS - Domestic Power System (National Power System consists of subsystems: power generation and electricity transmission and distribution of electricity and receiving electricity).

${ }^{2}$ Factory desert - a kind of flexible production system functioning with virtually no participation of people, or the human role is limited to monitoring and control of devices, components, etc. [17]. Development of the electricity 
internal organization of the system on the one hand, and with searching for higher levels of development control on the other. In order to obtain appropriate models of the DPS in the states space [5, 18], identification of the EPS in the MATLAB environment using System Identification Toolbox (SIT) was performed [19] for the consecutive rolling stages of development (with the step of one year), using data for the years 1946-2007 [15], which allowed to obtain a catalogue of matrices th (arx models) ${ }^{3}$.

In the next step, a catalogue of models of DPS development in the states space were constructed, using the mathematical system provided by the systems and control theory, followed by the examination of the behavior of the DPS using Control System Toolbox (CST), and i.a. using Evans' root loci for the visualization of structural and parametric changes in the DPS development. The model of development in the states space (ss) that was obtained, permits to generate an EPS development state vector. Consequently it allows to make a use of the achievements of the systems and control theory for the purpose of studying regularities in the development of the DPS as a control system. As a result, to design the development of the EE system as a developing system from point of view control theory [1, 5], system analysis [7, 9], smart grid systems $[4,8,17]$ and reliability systems were used [11].

\section{Identification of the DPS development}

In the process of identification, statistical data were used for the identification period of 30 years with the step of one year [15]. Research was conducted in the MATLAB and Simulink environments, using SIT and CST. As a result of identification, 33 parametric linear models (or ones brought to linear models) in the form of th matrices (arx models) were obtained as discrete models, transformed in the MATLAB environment into continuous models, and, then, transformed into continuous models in the states space (ss models) for 14 input variables and 4 single output variables (four MISO models). Identification was performed for 33 periods of the DPS development, and as a result, 33 matrices $\mathbf{A}, \mathbf{B}, \mathbf{C}$ and $\mathbf{D}$. Next, changes in both the degrees and the values of the elements of each matrix were examined [16]. In order to find a new model of the EP system, it is required to perform the identification of the DPS in the selected period, followed by the appropriate evaluative research, in accordance with the systems and control theory $[3,5,16]$.

As a result of identification, models of EPS development were obtained for respective periods of development $(\Delta \theta)$. First, processes in the DPS system and its subsystems were

system in the direction of unmanned factories associated with the concept of developing a system that changes can be studied on the basis of changes in the structure and elements of matrices $\mathbf{A}$ and $\mathbf{B}$ occur in models of state variables as a matrix containing knowledge concerning: the degree of internal organization of the system (matrix A) and control level (matrix B).

${ }^{3} \mathbf{T h}$ - a matrix of system identification result in the format of theta. It contains all the information about the model, its structure and parameters of estimators and their covariance estimate using. Theta matrix th has a defined dimension. Each element of the matrix theta contains specific information. And so the elements of the first row include estimates of variance parameters, sampling interval $\mathrm{T}$ and the parameters for, nb, nk, etc. The second line contains: FPE rate, year, month, day, minute and command a numerical code, which is generated by this model, in the third line model parameter estimates are in alphabetical order: $a 1, a 2, \ldots, b 0, b 1, \ldots$ (omitted wherein ones and zeros are present in the beginning of the polynomial), lines 4 to comprise $3+n$ covariance matrix estimate. 
subjected to identification, and then, the obtained models were used for the purpose of studying regularities in the development by conducting experiments in the MATLAB and Simulink environments using toolboxes such as SIT and CST [5, 16, 19]. Development systems, like dynamic systems, where measurement of change of the state of development in long time $\theta$ is a derivative of the state vector $x(\theta)$, may be described by the system of $\mathrm{n}$ differential equations of the first order. And so, for example, for the SISO object, a system of such equations may be presented in the general form, follows works $[5,16,19]$ :

$$
\frac{\mathrm{d} x(K, \theta, t=\text { const })}{\mathrm{d} \theta}=f_{1}(x(K, \theta, t=\text { const }), u(K, \theta, t=\text { const }), \quad z(K, \theta, t=\text { const }), \theta),
$$

and supplement it with the output equation:

$$
y(K, \theta, t=\text { const })=f_{2}(x(K, \theta, t=\text { const }), u(K, \theta, t=\text { const }), \quad z(K, \theta, t=\text { const }), \theta,
$$

where:

$x(K, \theta)$ is a state of system development,

$u(K, \theta)$ are input variables (input signal, inputs, input functions),

$z(K, \theta)$ are interferences,

$K$ is an ordered set of characteristic quantities of the EPS, which, in case of the developing system (system development) are quantities dependent on long time $\theta$, e.g. $K_{1}(\theta), K_{2}(\theta), \ldots$, $K_{n}(\theta)$ - they occur, e.g., in the form of component quantities of the vector $K(\theta)$ as an EPS development state vector, which, i.a., is an indicator of dynamics of the EPS development,

$\theta$ is a long time period [f.e. year, month, ...],

$t$ is a short time period [f.e. day, hour, ...].

\section{Assessment of development}

Model for the assessment of the system development contains ${ }^{4}$, i.a., $[5,16,19]$ : information about the EPS regarding the structure, parameters and characteristics of the system, criterion or a set of criteria for the assessment of the quality of the EPS development. It contains information about energy and power as a product of the system, algorithm for defining the value of the criterion, which includes information about the EPS and energy and power as a product of the system.

Assessment, in the systems and control theory, and particularly in the field of systems development engineering, involves the design and construction of the model of development based on appropriate information about changes in the system. Assessment criteria, subject of assessment, the object of assessment and the subject matter of assessment are the interrelated

${ }^{4}$ The article regards the assessment of development of the power system, and not the evaluation of the work (functioning, operation) power system. In assessing the power system is assessed themselves the References electricity transmission line length, evaluation of the work SEE (eg. determinants of the quality of current consumption patterns, etc.). UB from the point of view of the regularity of the development of the SEE are significant changes in the model parameters and changes in the structure of the model) [16]. 
elements that make up assessment, with the relation between the subject and the object of assessment being called the system of assessment. Various assessment criteria may be adopted, while always being tightly connected with the value of the system. Piotr Sienkiewicz (1987) stresses that assessment applies to selected values for the reason of specific system requirements [13].

Table 1. Structure of input variables. Source: [15]

\begin{tabular}{|c|c|c|c|c|c|c|c|c|c|c|c|c|c|c|}
\hline $\begin{array}{l}\stackrel{\mathscr{\Xi}}{\Xi} \\
\underbrace{2}\end{array}$ & 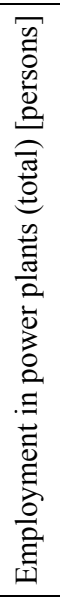 & 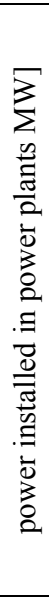 & 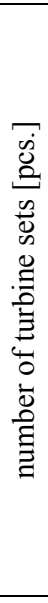 & 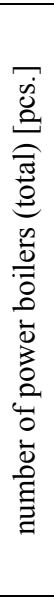 & 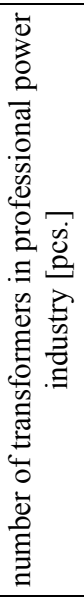 & 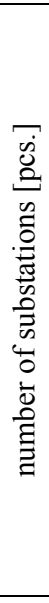 & 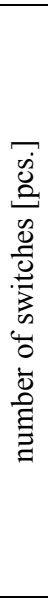 & 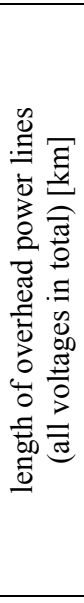 & 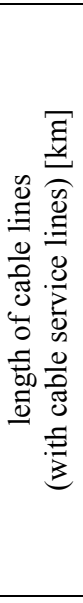 & 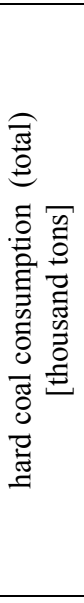 & 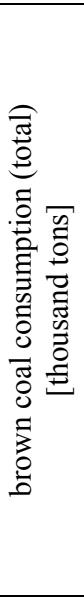 & 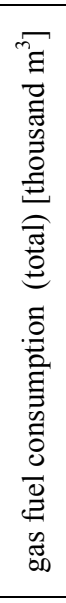 & 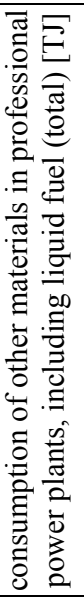 & 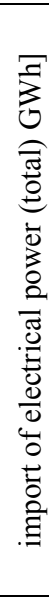 \\
\hline & $\mathbf{u}_{1}$ & $\mathbf{u}_{2}$ & $\mathbf{u}_{3}$ & $\mathbf{u}_{4}$ & $\mathbf{u}_{5}$ & $\mathbf{u}_{6}$ & $\mathbf{u}_{7}$ & $\mathbf{u}_{8}$ & $\mathbf{u}_{9}$ & $\mathbf{u}_{10}$ & $\mathbf{u}_{11}$ & $\mathbf{u}_{12}$ & $\mathbf{u}_{13}$ & $\mathbf{u}_{14}$ \\
\hline 1 & 2 & 3 & 4 & 5 & 6 & 7 & 8 & 9 & 10 & 11 & 12 & 13 & 14 & 15 \\
\hline 운 & $\underset{\text { ঠ্ }}{8}$ & 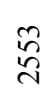 & $\stackrel{ \pm}{I}$ & $\stackrel{m}{m}$ & $\underset{\sim}{\stackrel{\sim}{\sim}}$ & $\underset{\stackrel{+}{+}}{\stackrel{\sim}{\sim}}$ & $\underset{\infty}{\infty}$ & \begin{tabular}{l}
8 \\
8 \\
0 \\
\hdashline
\end{tabular} & gे & $\begin{array}{l}8 \\
\stackrel{n}{n} \\
n\end{array}$ & \& & $n$ & $\stackrel{0}{2}$ & $\vec{\sim}$ \\
\hline . & $\ldots$. & $\ldots$ & $\ldots$ & $\ldots .$. & $\ldots \ldots$ & $\ldots$ & $\ldots$ & $\ldots$. & $\ldots$. & $\ldots . .$. & $\ldots .$. & ........ & $\ldots$ & $\ldots$. \\
\hline$\hat{o}$ & $\begin{array}{l}0 \\
\text { oे } \\
\text { nn }\end{array}$ & $\begin{array}{l}8 \\
\infty \\
\infty \\
n \\
n\end{array}$ & 点 & $\bar{n}$ & 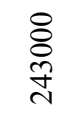 & $\begin{array}{l}\text { o } \\
\text { ñ } \\
\text { ñ }\end{array}$ & $\begin{array}{l}8 \\
\stackrel{\circ}{2} \\
\text { qे }\end{array}$ & 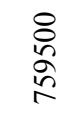 & $\begin{array}{l}\stackrel{8}{\circ} \\
\stackrel{n}{\circ} \\
\stackrel{2}{2}\end{array}$ & $\frac{n}{7}$ & $\begin{array}{l}\text { ¿ి } \\
\text { రิ }\end{array}$ & 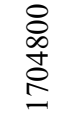 & $\begin{array}{l}8 \\
8 \\
n \\
n \\
m\end{array}$ & $\frac{N}{n}$ \\
\hline
\end{tabular}

In the discussed case of the DPS system development, the value of the system is connected with the demand for power and electrical energy. Hence, the assessment may involve examining the differences between the demand for system development usefulness and the achieved results as the system development potential.

Thus, the assessment of system development may be brought to needs assessment and to potential assessment, but the development system requiring as much security stream as it can afford with regards to the financial output, and the development system being able to produce as much power and electrical energy as its operational potential allows [16]. As a result, the assessment of developmental needs may be brought to the assessment of system inputs (usefulness income) and the potential to secure the development, and the assessment of develop- 
ment potential may be brought to the assessment of system outputs (operational potential, and usefulness output) - the relation (1) and (2).

Needs and potential assessment may be supplemented with development strengths assessment based on systems and control theory (assessment of complex supply-information quantities). Assuming that EPS state is defined as:

$$
s(K, \theta, t)=\langle Z(K, \theta, t), u(K, \theta, t)\rangle,
$$

with function $Z(K, \theta, t)$ and function $u(K, \theta, t)$ being called system state indexes, and the change in the state of the system being called the movement of the system, and a series of changes for distinguished moments of time being called the system trajectory $[5,16,19]$.

In order to perform the identification of the DPS system, appropriate numeric data were collected for the 14 input variables $\left(u_{1} \ldots-u_{14}\right)$ and 4 output variables $\left(y_{1}-y_{4}\right)$ for the years $1946-2007^{5}$, having the structure of the input variables presented in table 1 and the structure of output variables presented in Table 2 [16].

Identification of the DPS, for the periods of 30 years from the years 1946-2007, with the step of one year was conducted in the MATLAB and Simulink environment using SIT and CST. A catalogue of models of four subsystems (for 4 outputs) of MISO type, e.g. models for all (14) input variables and for the first output representing achievable power in power plants (total), which (33 in total) were presented in Table 3 (characteristics $A(q)$ ) and in Table 4 (characteristics $B(q)$ ). An example of the EPS system of arx133 type obtained with the accuracy of $99.14 \%$ for the period of 1969-1998 was presented in Fig. 1. The occurrence of certain regularities in the DPS models may be observed, mainly concerning the structure of the model and the value and structure of parameters $[16,18]$. In the majority of periods a model of arx131 type occurred, which was similar to the real data of the DPS system in $99.03 \%$. Moreover, models of arx 131 type for the set degree of accuracy did not differ in respect of the values of parameters.

Identification performed for the whole period of experiment data for the years 1946-2007 (62 years for output $y_{1}$ and for 14 inputs $u_{\mathrm{i}}$ ) generated model of arx 133 type with the accuracy of $99.14 \%$ of the following form 16,19$]$ :

$$
A(q) \cdot y(\theta)=B(q) \cdot u(\theta)+e(\theta),
$$

where:

$$
\begin{aligned}
A(q) & =1-0.4884 \pm 0.2126 \cdot q^{-1} \\
B 1(q) & =-0.05335 \cdot( \pm 0.1809) \cdot q^{-3}-0.1004 \cdot( \pm 0.124) \cdot q^{-4}+0.09545 \cdot( \pm 0.1555) \cdot q^{-5} \\
B 2(q) & =0.4866 \cdot( \pm 0.3725) \cdot q^{-3}+0.2477 \cdot( \pm 0.2733) \cdot q^{-4}+0.6879 \cdot( \pm 0.2626) \cdot q^{-5}
\end{aligned}
$$

${ }^{5}$ Data have been obtained, among others, of data considered to be the essence of the point of view of planning the development of the power system, which has been published in the annals of Polish Electrical Power Statistics. 
$q$ is a time shift operator, which works like this: $y(\theta) \cdot q^{-1}=y(\theta-1)$, $\theta$ is a long time period [year].

Table 2. Output variables structure. Source [15]

\begin{tabular}{|c|c|c|c|c|}
\hline 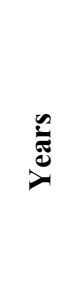 & 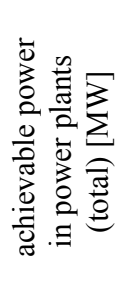 & 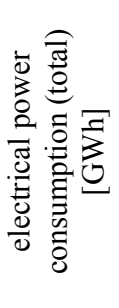 & 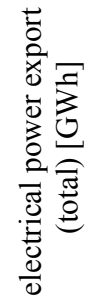 & 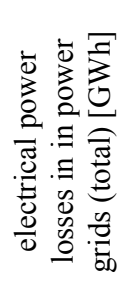 \\
\hline & $y_{1}$ & $\mathbf{y}_{2}$ & $\mathbf{y}_{3}$ & $\mathbf{y}_{4}$ \\
\hline 1 & 16 & 17 & 18 & 19 \\
\hline 1946 & 2004 & 8000 & 92 & 1517 \\
\hline .......... & ……...... & ........... & ............ & ........... \\
\hline 2007 & 34877 & 162500 & 13110 & 26950 \\
\hline
\end{tabular}

The course of output $y_{1}$ (power achievable in power plants (total) [MW]) of the arx133 model of the DPS system was presented in Fig. 1 [16]. As a result of transformation of the arx 133 model from the discrete form (4) into a discrete model in the states space, matrices $\mathbf{A}, \mathbf{B}$, C, D, K and X0 are obtained [5, 16, 19]. Transformation of a discrete model arx 133 of the DPS system into a continuous model using the TUSTIN method results in obtaining a model th133 $[5,10,16]$. Further transforming a continuous model th133 into a continuous model in the states space ss using the function thss (th133) [16] matrices with dimensions: $\mathbf{A}(71 \times 71)$, $\mathbf{B}(71 \times 14), \mathbf{C}(1 \times 71), \mathbf{D}(1 \times 14), \mathbf{K}(71 \times 1), \mathbf{X 0}(71 \times 1)$ were obtained.

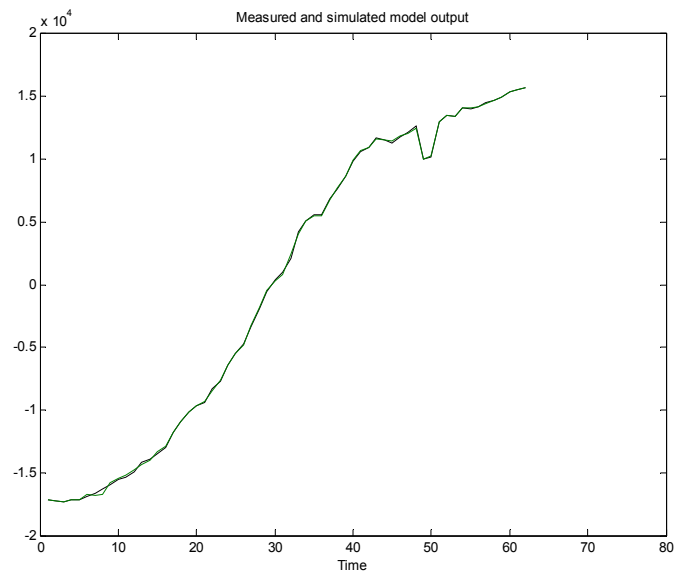

Fig. 1. Courses of output variable $y_{1}$ (power achievable in power plants (total) $[\mathrm{MW}]$ ) of the arx133 model and the real DPS system considering 14 input variables (model concordance with the EP system - 99.14\%), $y$ axis - amplitude of the subsystem that generates $\mathrm{y}_{1}$ and its model, $x$ axis (Time) - long time [years] [17]

Removing the average from the model allows to generate a model arx131. As a result of transformation of the model of the DPS system from the discrete form arx131 into the conti- 
nuous form using TUTSIN method, using function $\mathrm{d} 2 c$ (arx131, 'TUTSIN'), the model th131 was obtained.

Finally, following transformation into a continuous model ss in the states space - DPS model in the form:

$$
\begin{aligned}
& \dot{x}_{1}=0.1342 \cdot x_{1}+x_{2}+0.3430 \cdot u_{1}-0.1965 \cdot u_{2}-5.1912 \cdot u_{3}-14.5048 \cdot u_{4}+0.1554 \cdot u_{5}+ \\
& -0.0275 \cdot u_{6}-0.2766 \cdot u_{7}-0.0074 \cdot u_{8}+0.1073 \cdot u_{9}+0.2976 \cdot u_{10}+0.0623 \cdot u_{11}+ \\
& -0.0100 \cdot u_{12}-0.01287 \cdot u_{13}+0.3019 \cdot u_{14}, \\
& \dot{x}_{2}=x_{3}-0.0539 \cdot u_{1}-0.7748 \cdot u_{2}+0,3863 \cdot u_{3}+9.7155 \cdot u_{4}-0.0529 \cdot u_{5}+ \\
& -0.0275 \cdot u_{6}-0.2766 \cdot u_{7}-0.0074 \cdot u_{8}+0.1073 \cdot u_{9}+0.2976 \cdot u_{10}+0.0623 \cdot u_{11}+ \\
& -0.0100 \cdot u_{12}-0.01287 \cdot u_{13}+0.3019 \cdot u_{14}, \\
& \dot{x}_{3}=0.1443 \cdot u_{1}+0.3264 \cdot u_{2}+29.5244 \cdot u_{3}+14.1706 \cdot u_{4}+0.0680 \cdot u_{5}+ \\
& +0.0067 \cdot u_{6}-0.6104 \cdot u_{7}+0.0264 \cdot u_{8}-0.0288 \cdot u_{9}+0.1541 \cdot u_{10}+0.0474 \cdot u_{11}+ \\
& -0.0096 \cdot u_{12}+0.0237 \cdot u_{13}+0.0266 \cdot u_{14}, \\
& y_{1}=x_{1}, \text { for } C_{11}=1 .
\end{aligned}
$$

Therefore, a continuous linear model of the DPS is described by three state variables, which may be interpreted as follows:

$x_{1}$ is electricity energy that can be generated in power plants (total) during a year [kWh], which was taken based on the analysis of the output equation $\left(y_{1}=c_{11} x_{1}\right)$, assuming that in matrix $\mathbf{C}$ element $c_{11}=1$ [1/year],

$x_{2}$ is the achievable power of generators [MW], which was taken based on the first state equation,

$x_{3}$ is the rate of changes in the achievable power of generators during a year [MW/year], which was interpreted based on the second state equation.

It may be noticed that changes of the third state variable only depend on input variables, with the input variable $\mathrm{u}_{3}$ (number of turbine sets) and $u_{4}$ (number of power boilers) having the greatest positive impact on the change of the value of the state variable $x_{3}$. Input variables $u_{1}$ (employment in power plants), $u_{9}$ (length of cable lines) and $u_{12}$ (consumption of gas fuels) have the negative impact.

In turn, among models obtained as a result of moving identification (Table 3 and 4), it is worth noticing that only six structures of discrete models occurred, i.e. arx131 (for periods: 1-4, 7-11, 14, 17-19, 23, 25-26, 28-32), arx135 (for periods: 3-4), arx132 (for periods: 12, 15, 27), arx134 (for periods: 13, 22), arx133 (for periods: 16, 20, 24), arx619 (for period 33), i.e. six structural changes occurred in the DPS in the years 1946-2007 and in the scope of the experiment.

Analysis of Equation (5) shows that the value of the output variable $y_{1}(\theta)$ is most strongly influenced by output variables for the previous year and output variables for the last three years, with the influence being positive or negative depending on the year. 
Table 3. Coefficients at operators $q^{i}(i=1-6)$ in polynomial $A 1(q)$

\begin{tabular}{c|c|c|c|c|c|c|c}
\hline \multicolumn{7}{c}{$A(\boldsymbol{q})$} \\
\hline $\boldsymbol{\theta}$ & Period & $\boldsymbol{q}^{-1}$ & $\boldsymbol{q}^{-2}$ & $\boldsymbol{q}^{-3}$ & $\boldsymbol{q}^{-4}$ & $\boldsymbol{q}^{-5}$ & $\boldsymbol{q}^{-6}$ \\
\hline 1 & $46-75$ & -0.1342 & 0 & 0 & 0 & 0 & 0 \\
\hline 2 & $47-76$ & -0.1342 & 0 & 0 & 0 & 0 & 0 \\
\hline 3 & $48-77$ & -0.1342 & 0 & 0 & 0 & 0 & 0 \\
\hline$\ldots$ & $\ldots$ & $\ldots$ & $\ldots$ & $\ldots$ & $\ldots$ & $\ldots$ & $\ldots$ \\
\hline 31 & $76-05$ & -0.1342 & 0 & 0 & 0 & 0 & 0 \\
\hline 32 & $77-06$ & -0.1342 & 0 & 0 & 0 & 0 & 0 \\
\hline 33 & $78-07$ & -0.7413 & 0.07914 & 0.04467 & -17.04 & 1.427 & -0.2381 \\
\hline
\end{tabular}

It may be observed that the past has the strongest impact on variable $u_{4}$ (total number of power boilers). It should also be noted that there are regularities in the DPS models, especially regularities concerning the structure of the model and the values of the parameters. In general, model of arx131 type prevailed in most periods, which model is similar to real data of DPS in $99.03 \%$. Moreover, these models did not differ as regards the values of parameters (there occurred slight parametric changes of the system).

Table 4. Coefficients at operators $q^{-i}(i=1-9)$ in polynomial $B_{1}(q)$

\begin{tabular}{c|c|c|c|c|c|c|c|c|c|c}
\hline $\boldsymbol{\theta}$ & Period & $\boldsymbol{q}^{-\mathbf{1}}$ & $\boldsymbol{q}^{-\mathbf{2}}$ & $\boldsymbol{q}^{-\mathbf{3}}$ & $\boldsymbol{q}^{-\mathbf{4}}$ & $\boldsymbol{q}^{-\mathbf{5}}$ & $\boldsymbol{q}^{-\mathbf{6}}$ & $\boldsymbol{q}^{-\mathbf{7}}$ & $\boldsymbol{q}^{-\mathbf{8}}$ & $\boldsymbol{q}^{-\boldsymbol{9}}$ \\
\hline $\mathbf{1}$ & $46-75$ & 0.343 & -0.05387 & -0.1443 & 0 & 0 & 0 & 0 & 0 & 0 \\
\hline $\mathbf{2}$ & $47-76$ & 0.343 & -0.05387 & -0.1443 & 0 & 0 & 0 & 0 & 0 & 0 \\
\hline $\mathbf{3}$ & $48-77$ & 0.343 & -0.05387 & -0.1443 & 0 & 0 & 0 & 0 & 0 & 0 \\
\hline$\ldots$ & $\ldots$ & $\ldots$ & $\ldots$ & $\ldots$ & $\ldots$ & $\ldots$ & $\ldots$ & $\ldots$ & $\ldots$ & $\ldots$ \\
\hline $\mathbf{3 1}$ & $76-05$ & 0.343 & -0.05387 & -0.1443 & 0 & 0 & 0 & 0 & 0 & 0 \\
\hline $\mathbf{3 2}$ & $77-06$ & 0.343 & -0.05387 & -0.1443 & 0 & 0 & 0 & 0 & 0 & 0 \\
\hline $\mathbf{3 3}$ & $78-07$ & 0 & 0 & 0 & 0 & 0 & 0 & 0 & 0 & -20.12 \\
\hline
\end{tabular}

As a result, the following discrete model of the DPS development for the subsystem of achievable power in power plants $\left(y_{1}\right)$, which, following the replacement of time shift operator $q^{-i}$ with $\theta$ using the rule that e.g.:

$y_{1}(\theta) q^{-1}=y_{1}(\theta-1)$ generates the following model: 


$$
\begin{aligned}
& y_{1}(\theta)=0.1342 \cdot y_{1}(\theta-1)-0.1342 \cdot u_{1}(\theta-1)-0.05387 \cdot u_{1}(\theta-2)-0.1443 u_{1}(\theta-3)-0.1965 u_{2}(\theta-1)+ \\
& -0.7748 u_{2}(\theta-2)+0.3264 u_{2}(\theta-3)-5.191 \cdot u_{3}(\theta-1)+0.3683 u_{3}(\theta-2)+29.52 \cdot u_{3}(\theta-3)+ \\
& -14.5 \cdot u_{4}(\theta-1)+9.715 \cdot u_{4}(\theta-2)+14.17 \cdot u_{4}(\theta-3)+0.1554 u_{5}(\theta-1)-0.05293 u_{4}(\theta-2)+ \\
& +0,06803 u_{4}(\theta-3)-0.01336 u_{6}(\theta-1) 0.02755 u_{6}(\theta-2)+0.006739 u_{6}(\theta-3)-0.05234 u_{7}(\theta-1)+ \\
& +9.715 \cdot u_{7}(\theta-2)-0.6104 u_{4}(\theta-3)-0.002718 u_{8}(\theta-1)-0.007408 u_{8}(\theta-2)+0.2639 u_{8}(\theta-3)+ \\
& -0.03015 u_{9}(\theta-1)+0.1073 u_{9}(\theta-2)-0.02883 u_{9}(\theta-3)+0.08841 u_{10}(\theta-1)+0.2976 u_{10}(\theta-2)+ \\
& +0.1541 \cdot u_{10}(\theta-3)+0.131 \cdot u_{11}(\theta-1)+0.06231 u_{11}(\theta-2)-0.04736 u_{11}(\theta-3)+0.01546 u_{12}(\theta-1)+ \\
& -0.009961 u_{12}(\theta-2)-0.009608 u_{12}(\theta-3)-0.02837 \cdot u_{13}(\theta-1)-0.1287 \cdot u_{13}(\theta-2)+0.2337 \cdot u_{13}(\theta-3)+ \\
& -0.2198 u_{14}(\theta-1)+0.3019 u_{14}(\theta-2)+0.02655 u_{14}(\theta-3)+e(\theta) .
\end{aligned}
$$

Therefore, the sought value of achievable power in power plants (total) $y_{1}[\mathrm{MW}]$, e.g. in the year $\theta=2010$, is influenced by the following quantities: the value of achievable power for the previous year, i.e. for the year $\theta$-1 (i.e. 2009) and all input variables amounting to 14 for the three previous years, i.e. for the year 2009 (for: $\theta$-1), i.e. 2008 (for: $\theta$-2), i.e. 2007 (for: $\theta-3)$. Further, following the transformation of a selected discrete moving model of DPE (arx131) into a discrete model th131, and then into a continuous model in the states space ss, the following state equations matrices were obtained:

$$
\mathbf{A 2 0 c}=\left[\begin{array}{ccc}
0.1342 & 1.0000 & 0 \\
0 & 0 & 1.0000 \\
0 & 0 & 0
\end{array}\right],
$$

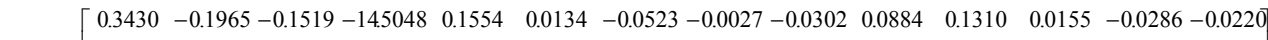

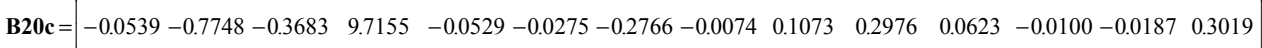

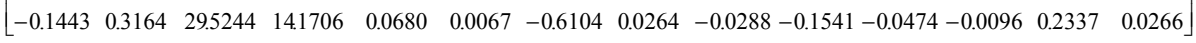

$$
\begin{aligned}
& \mathbf{C 2 0} \mathbf{c}=\left[\begin{array}{lll}
1 & 0 & 0
\end{array}\right],
\end{aligned}
$$

$$
\mathbf{D 2 0} \mathbf{c}=\left[\begin{array}{llllllllllllll}
0 & 0 & 0 & 0 & 0 & 0 & 0 & 0 & 0 & 0 & 0 & 0 & 0 & 0
\end{array}\right],
$$

$$
\mathbf{K 2 0 c}=\left[\begin{array}{c}
0.1342 \\
0 \\
0
\end{array}\right], \quad \mathbf{X 0 2 0} \mathbf{c}=\left[\begin{array}{l}
0 \\
0 \\
0
\end{array}\right] .
$$

It can easily be noticed that a linear continuous model of the DPE development of arx131 type (7), obtained for the above mentioned 30-year periods is analogous to the model obtained for numeric data for the whole measurement period, i.e. for the years 1946-2007. 


\section{Changes parametric and structural development of the NPS}

On the basis of the identification of up to 14 input variables and one of the four output variables (MISO models for generating capacity in total) defines the minimum statistic figures of the period of 30 years, which was used in the identification of moving to obtain 33 models of development NPS (consecutively for years: 1946-1975, 1947-1976, ... 1978-2007).

In most periods were discrete parametric models of type arx131, in line with the actual data NES system in $99.03 \%$, which basically do not differ too parameter values. Moreover, the resulting model of development KSE in an experiment carried out for identification of the figures for the whole period under examination, identification, that is for 62 years (data from the years 1946 to 2007) was in line with the actual data KSE at $99.14 \%$ (difference of $0.11 \%$ in relation to the above. arx131 model).

Examples of the results are more fully described in, among others, in the monograph [16] selected polynomials $A(q)$ and polynomials $B i(q)$. The analysis of the obtained results, above all with the same structures and model parameters obtained in identification of moving results include the occurrence of identical six discrete structures SEE the form of development models:

1) $\operatorname{arx} 131-$ parameters for $=1, \mathrm{nb}=3, \mathrm{nk}=1$ for periods: $1-4,7-11,14,17-19,21,23,25-26$, 28-32,

2) $\operatorname{arx} 135$ - with parameters for $=1, \mathrm{nb}=3, \mathrm{nk}=5$ periods: $5-6$,

3) arx 132 - with parameters for $=1, \mathrm{nb}=3, \mathrm{nk}=2$ periods: $12,15,27$,

4) $\operatorname{arx} 134$ - parameters for $=1, n b=3, n k=4$ for periods of 13,22 ,

5) $\operatorname{arx} 133$ - parameters for $=1, \mathrm{nb}=3, \mathrm{nk}=3$ periods: $16,20,24$,

6) $\operatorname{arx} 619$ - parameters for $=6, \mathrm{nb}=1, \mathrm{nk}=9$ period 33 .

It was noted that in the years 1946-1978 the development model of the system was the development of parametric, there were no structural changes KSE development model. In the years 1978-2007 17 structural changes occurred in the NPS development model, they were generally combined with parametric change that caused instability in the development of the NPS system model. Structural changes NPS system model development occurred each year (year on year) in six periods, it is in years: 1978-1979, 1980-1981, 1985-1991, 1993-1999, 2000-2002, 2006-2007.

Thus, from the point of view of eg. the output variable $\mathrm{y}_{1}$ (model MISO), so from the standpoint of the subsystem generating capacity of the power plants controlled by a total of 14 input variables can speak about the stability of the NPS system development model in the years 1946-1978, 1979-1980, 1981-1985, 1991-1993, 1999-2000, 2001-2006 there were only parametric changes. On the basis of the above received development models for rolling periods and on the basis of the model of development for the entire survey period (years 1946-2007) can also infer the behavior of the NPS. Mileage $y_{1}$ (energy produced in power plants (total) [MW]) model arx133 NPS system was included in Fig. 1.

As indicated in the analysis of the two waveforms (Fig. 1), it is the development of the NPS system and its model of large structural changes occurred in the period 1985-2002 (periods of development 40-57), in particular in 1993-1997 (periods of development 48-52). 
Thus, the presented results of the past studies are consistent in this part with the results obtained, for example of the Wroclaw Technical University for a much shorter time series system load, were distinct periods were also stable (6 periods) and unstable (6 periods) for NPS system development. To generalize the results presented in this study the test results can talk about distinct structural changes in the years 1985-2002 as well as the stable development of the NES system in the years 19461984 (with minor structural changes) and return to a relatively stable development in 2003-2007, with little structural change in 2007. Worth mentioning is the fact that these findings would arise from the analysis of incidence and course of the elemental Evans $[3,5,16]$.

For these reasons, the proposed method can be used to check the validity of development in the case of significant structural changes in the NPS system, for example due to intensive development of distributed generation, the introduction of nuclear fuel or the different climatic and social factors. The identification of this type of model is associated with the meeting of the need to sufficiently long time series in this respect.

\section{Models of the DPS development in the states space}

Model of the DPS system development developed based on the experiment data for the years 1946-2007 [15] for 14 input variables and for one output $\mathrm{y}_{1}$ that represents the total achievable power in power plants [MW] (MISO model) written in the states space using state and output equations (7) may be described in the matrix-vector form as follows:

$$
\left[\begin{array}{l}
\dot{x}_{1} \\
\dot{x_{2}} \\
\dot{x_{3}}
\end{array}\right]=\left[\begin{array}{ccc}
0.1342 & 1 & 0 \\
0 & 0 & 1 \\
0 & 0 & 0
\end{array}\right]\left[\begin{array}{l}
x_{1} \\
x_{2} \\
x_{3}
\end{array}\right]+
$$

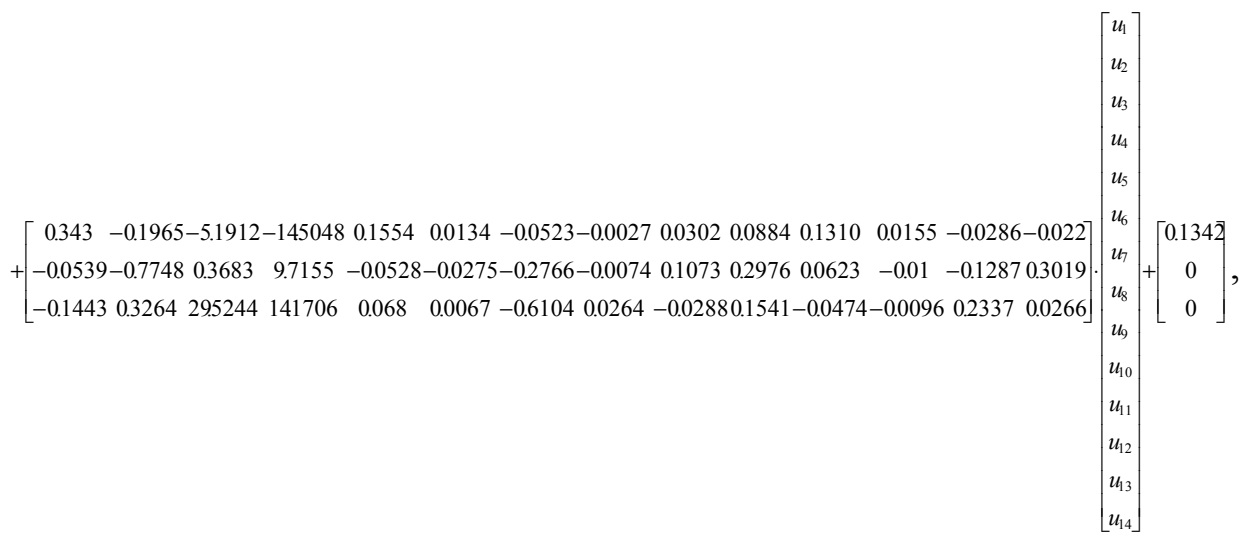




$$
y_{1}=\left[\begin{array}{lll}
1 & 0 & 0
\end{array}\right] \cdot\left[\begin{array}{l}
x_{1} \\
x_{2} \\
x_{3}
\end{array}\right],
$$

where:

$x_{1}$ is a state variable that can be interpreted as a maximum electricity energy that can be generated in power plants (total) $[\mathrm{kWh}]$,

$x_{2}$ is a state variable that can be interpreted as achievable power of generators [MW],

$x_{3}$ is a state variable that can be interpreted as a rate of changes in the achievable power of generators during a year [MW/year].

As a result of further transformations, the following is finally obtained [16]:

$\mathbf{X} k s e=e^{\mathbf{A} \cdot \theta} \cdot \mathbf{B} \cdot u(\theta)=\left[\begin{array}{ccc}e^{0.1342 \cdot \theta} & \frac{1}{0.1342}\left(e^{0.1342 \cdot \theta)}-1(\theta)\right) & \frac{1}{0.1342} \cdot\left(\frac{1}{0.1342} \cdot e^{0.1342 \cdot \theta)}-1(\theta)\right. \\ 0 & 1(\theta) & \theta \\ 0 & 0 & 1(\theta)\end{array}\right] *$

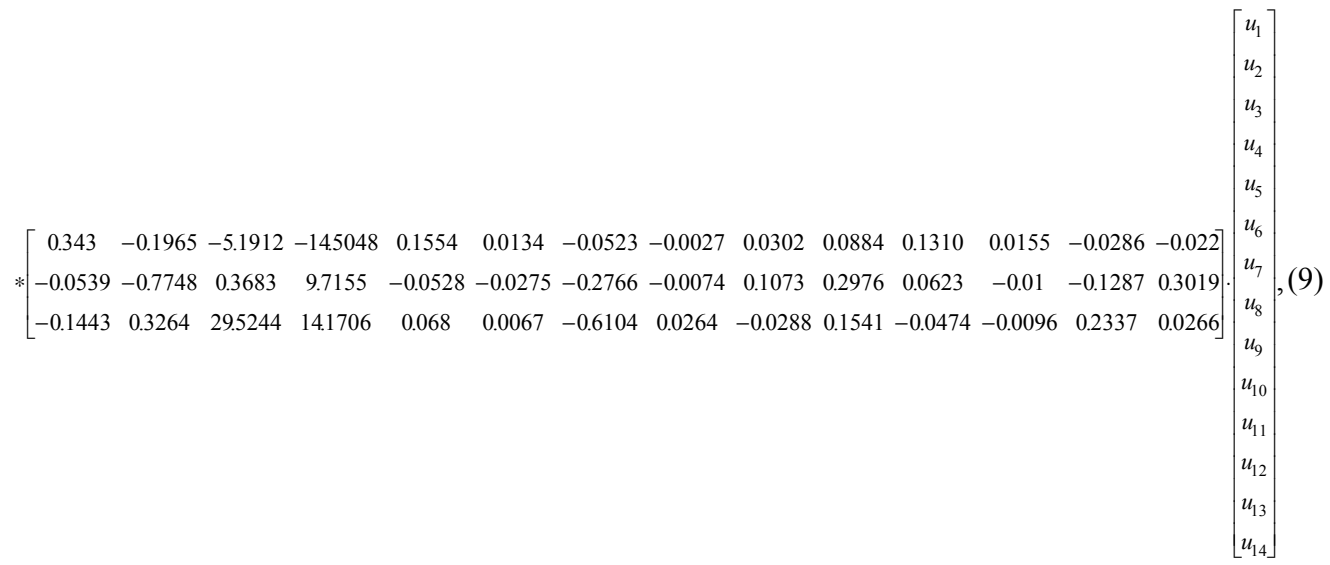

and

$$
\mathbf{Y k s e}_{1}=\mathbf{C} \cdot \mathbf{X} k s e=\left[\begin{array}{lll}
1 & 0 & 0
\end{array}\right] \cdot \mathbf{X} k s e .
$$

The results of the DPS responses obtained in Simulink (output variable $y_{1}$ ) to input functions such as: unit step $1(\theta)$, Dirac's impulse function $\delta(\theta)$ and $\sin (\theta)$ are presented in Table 5 , with the solution to the set of equations of state variables are 3 state variables expressed as follows: 


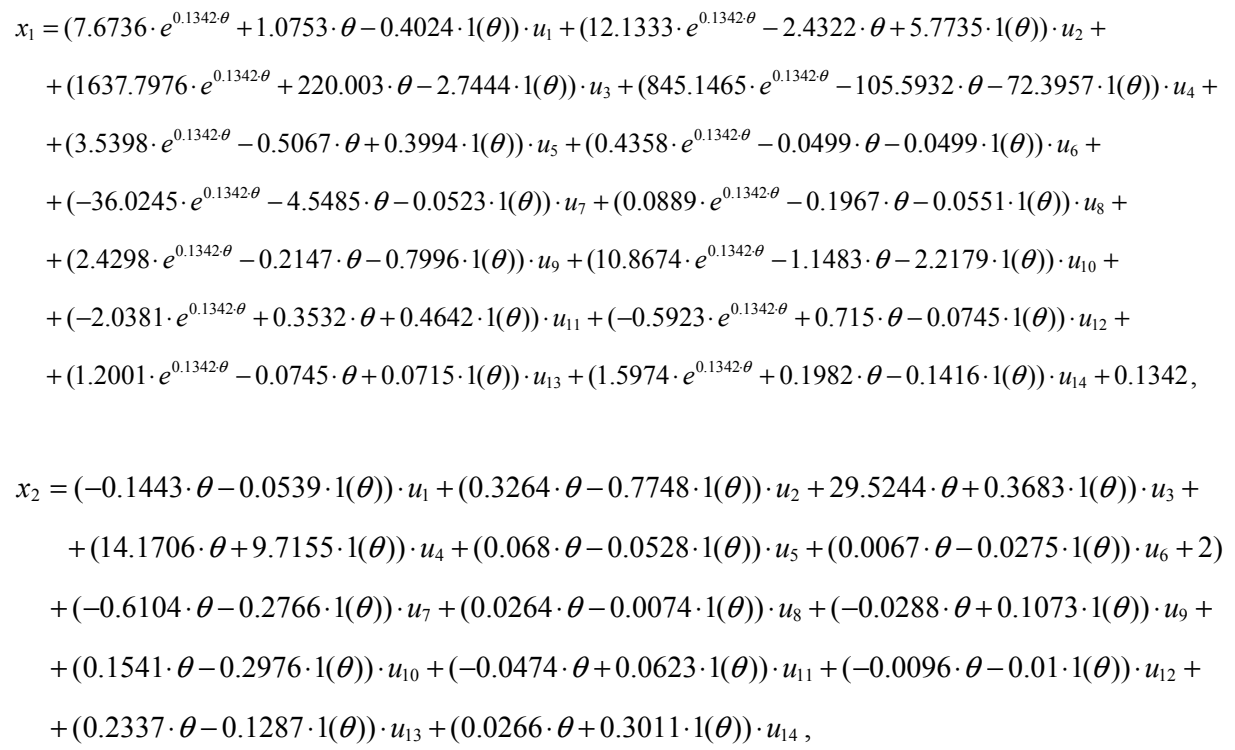

and the output variable:

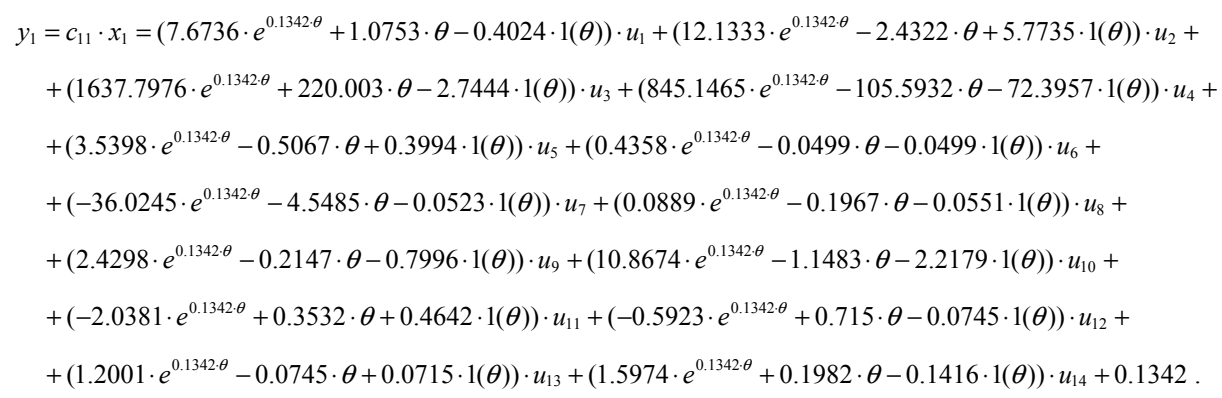

\section{Interpretation of results in the category of unmanned factories}

Design of a model of development based on statistical numeric data in the category of a smart factory (as unmanned factory) e.g. for the purpose of studying directions of development of the domestic electrical power system requires detailed structural and parametric research. In this work, a computational example will be shown, based on the MISO model for the above mentioned 14 input variables and one output variable $y_{1}(\theta)$ representing total achievable power in power plants.

As a result of the DPS identification for the periods of 30 years with the step of 5 years, using polish statistical data for the years 1946-2007 (62 years), eight parametric models of the 
DPS were obtained as discrete models arx. They were later on transformed into eight continuous parametric models th, further transformed into continuous models in the state space (ss). In this way, eight matrices $\mathbf{A}$ and eight matrices $\mathbf{B}$ were obtained. Dimensions of matrices are shown in Table 5.

Table 5. Selected dimensions of matrices of models of the DPS development state variables

\begin{tabular}{c|c|c|c|c|c}
\hline \multirow{2}{*}{ No. } & \multirow{2}{*}{ The test periods } & \multicolumn{4}{|c}{ Matrix dimensions } \\
\cline { 2 - 5 } & $1946-1975$ & A & B & C & D \\
\hline 1 & $1951-1980$ & $1 \times 1$ & $1 \times 14$ & $1 \times 1$ & $1 \times 14$ \\
\hline 2 & $1956-1985$ & $16 \times 16$ & $16 \times 14$ & $1 \times 16$ & $1 \times 14$ \\
\hline 3 & $1961-1990$ & $15 \times 15$ & $15 \times 14$ & $1 \times 15$ & $1 \times 14$ \\
\hline 4 & $1966-1995$ & $1 \times 1$ & $1 \times 14$ & $1 \times 1$ & $1 \times 14$ \\
\hline 5 & $1971-2000$ & $7 \times 7$ & $7 \times 14$ & $1 \times 7$ & $1 \times 14$ \\
\hline 6 & $1976-2005$ & $5 \times 5$ & $5 \times 14$ & $1 \times 5$ & $1 \times 14$ \\
\hline 7 & $1978-2007$ & $3 \times 3$ & $3 \times 14$ & $1 \times 3$ & $1 \times 14$ \\
\hline 8 & & $6 \times 6$ & $6 \times 14$ & $1 \times 6$ & $1 \times 14$ \\
\hline
\end{tabular}

The analysis of changes of the model's dimensions indicates structural changes in the development of the domestic electrical power system in the years 1946-2007. The simplest models occurred in the years 1946-1975 and 1961-1990, and the most complex ones in the years 1951-1980 and 1956-1985. Changes of the values of selected elements of matrix A responsible for the degree of internal organization of the DPS, and matrix B responsible for the level of control are presented in Table 6 .

Table 6. Selected dimensions of matrices of models of the DPS development state variable

\begin{tabular}{c|c|c|c|c|c|c|c|c}
\hline \multirow{2}{*}{ No. } & \multicolumn{7}{|c}{ The values of selected elements of the matrix } \\
\cline { 3 - 9 } & \multirow{2}{*}{ The test periods } & \multicolumn{3}{|c}{$\mathbf{A}$} & \multicolumn{3}{c}{ B } \\
\cline { 3 - 9 } & & $\mathbf{a}_{11}$ & $\mathbf{a}_{12}$ & $\mathbf{a}_{21}$ & $\mathbf{b}_{11}$ & $\mathbf{b}_{18}$ & $\mathbf{b}_{19}$ & $\mathbf{b}_{21}$ \\
\hline 1 & $1946-1975$ & 0.5109 & 0 & 0 & 0.1566 & 0.0094 & 0.1153 & 0 \\
\hline 2 & $1951-1980$ & 1.8773 & 1 & 0.579 & 0 & 0 & 0 & 0 \\
\hline 3 & $1956-1985$ & 1.8934 & 0.1958 & 0 & 0 & 0 & 0 & 1 \\
\hline 4 & $1961-1990$ & 0.5109 & 0 & 0 & 0.1566 & 0.0094 & 0.1153 & 0 \\
\hline 5 & $1966-1995$ & 0.4649 & 1 & -0.123 & 0.8884 & 0.0235 & 0.1095 & 0 \\
\hline 6 & $1971-2000$ & 1.2467 & 1 & -0.0257 & 0.8193 & 0.0372 & -0.0092 & 0 \\
\hline 7 & $1976-2005$ & 0.2617 & 1 & 0.1323 & 0.905 & 0.0203 & -0.0424 & 0 \\
\hline 8 & $1978-2007$ & 0.7824 & 1 & -0.02224 & 0.53 & 0.0288 & -0.1557 & 0 \\
\hline
\end{tabular}


Selected courses of changes of elements of matrix $\mathbf{A}$ are shown in plots in Table 7. The course of changes of the above mentioned values of elements of matrix $\mathbf{A}$ indicates that in the studied period, the influence of state variable $x_{2}$ on the level of the internal organization of the DPS system, expressed by means of changes of state variable $x_{1}$ increased, and the influence of state variable $x_{1}$ on the level of the internal organization of the DPS system expressed by means of changes of state variable $x_{1}$ decreased, and the influence of the state variable $x_{1}$ on the degree of the internal organization of the DPS system expressed by means of changes of state variable $x_{2}$ decreased.

Table 7. Parametric changes of the DPS system development resulting from changes of elements of matrix A. Mark: $x$-axis - time, marking the $y$-axis in the remarks

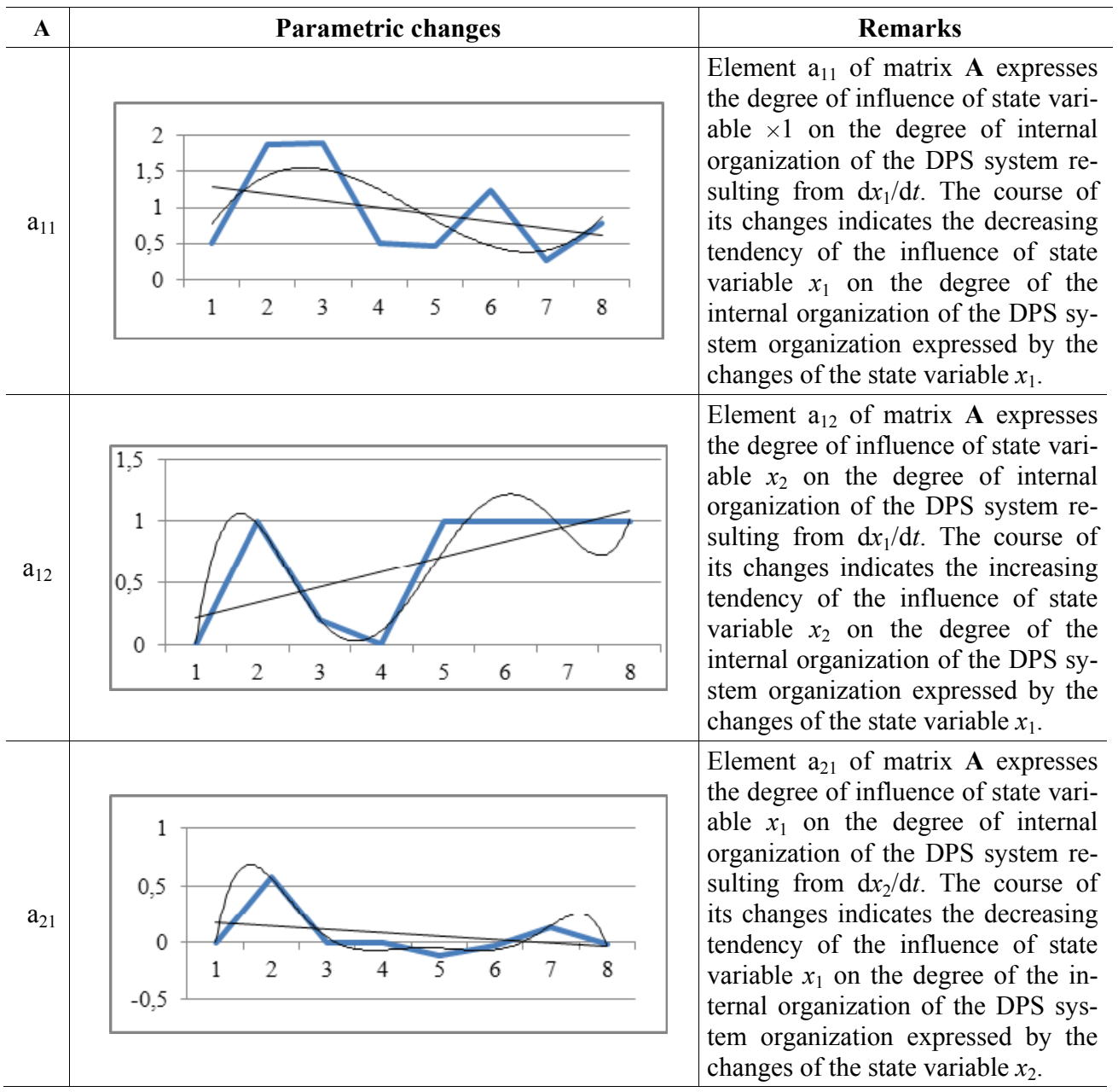

By analyzing the courses of state variable $x_{1}$ (electricity energy, which can be generated during a year) it can be noticed (Fig. 2 - Fig. 6) that as a result of excitation of inputs with the sinusoidal function the course of the state variable is still exponential (after a very short unba- 


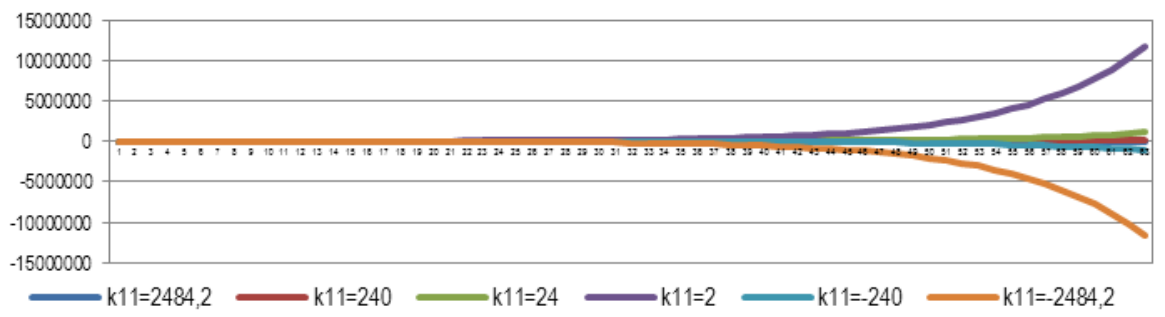

Fig. 2. Courses of the expotential component $\mathrm{k}_{11} \cdot e^{s 3 \cdot \theta}$ of the state variable $x_{1}$ (electrical power that can be produced during a year) relative to $\mathrm{k}_{11}$ (gain coefficient of the process of the DPS development), axis $y$ - the value the exponential state variable $x_{1}$, axis $x$-periods of development (time $\theta$ )

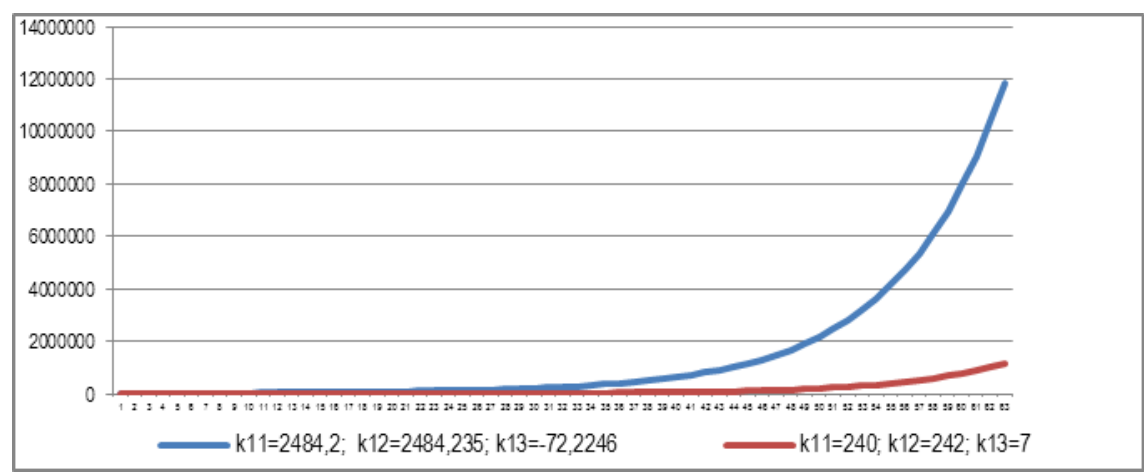

Fig. 3. Courses of the rectilinear component $\mathrm{k}_{12} \cdot \theta$ of the state variable $x_{1}$ (electrical power that can be produced during a year) relative to $\mathrm{k}_{12}$ (gain coefficient of the process of the DPS development), axis $y$ - the value the exponential state variable $x_{1}$, axis $x$ - Periods of development (time $\theta$ )

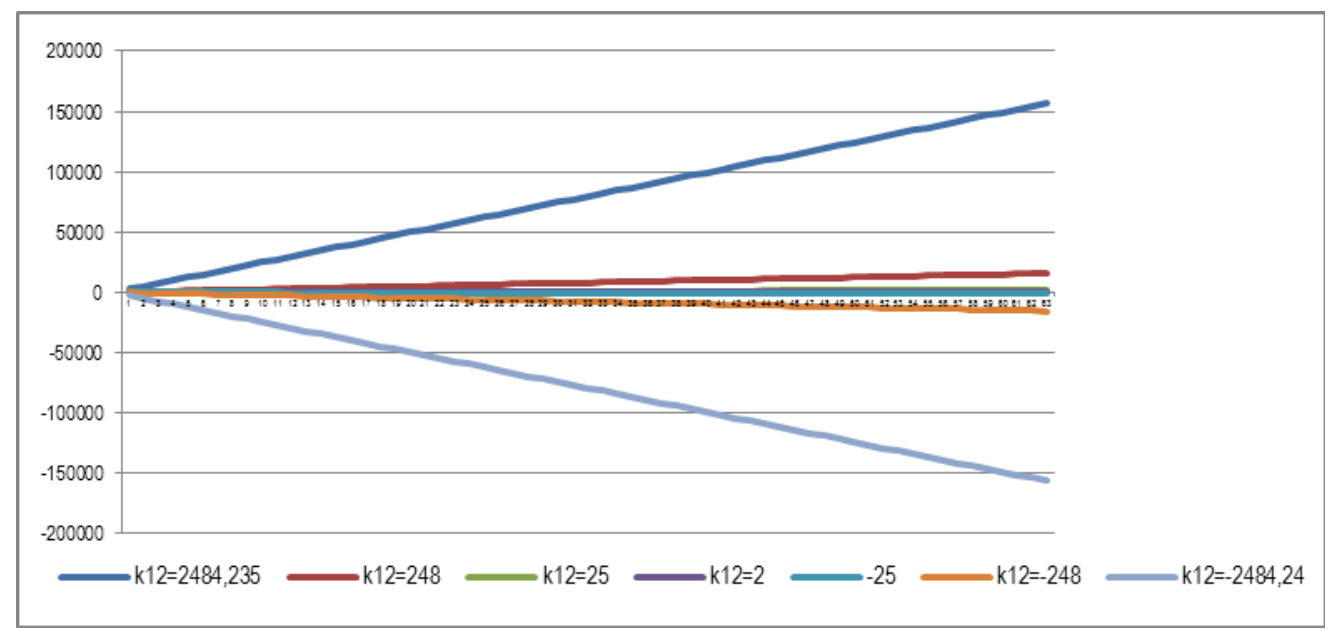

Fig. 4. Courses of the state variable $x_{1}$ (electrical power that can be produced during a year) without consideration to sinusoidal input function relative to $\mathrm{k}_{11}, \mathrm{k}_{12}$ and $\mathrm{k}_{13}$ (gain coefficient of the process of the DPS development), axis $y$-value of 3 components (expotential, rectilinear and unit step) of state variable $x_{1}$, axis $x$-periods of development (long time $\theta$ ) 
lancing), and decrease of gain coefficients by one order of magnitude results in its course being flattened (resistance to sinusoidal input function). Artificial intelligence methods for design and exploitation of the DPS, including evolutionary methods, artificial neural networks and expert systems as regards the DPS development based on the control theory $[2,5]$, smart grids $[6,17]$, intelligent systems $[8,14]$ and unmanned factories $[3,16]$ may be used for further research.

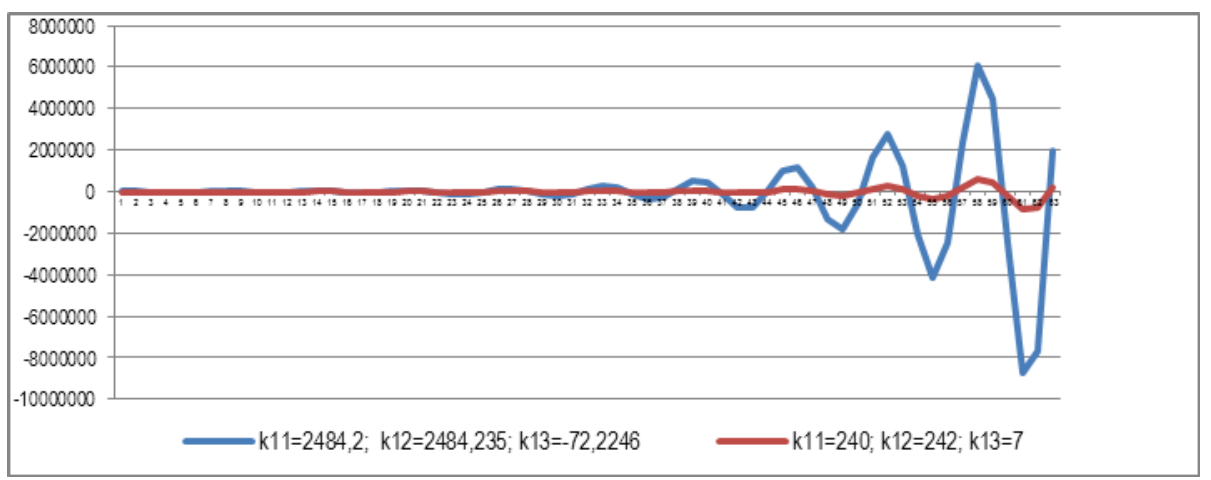

Fig. 5. Courses of the state variable $x_{1}$ (electrical power that can be produced during a year) relative to $\mathrm{k}_{11}, \mathrm{k}_{12}$ and $\mathrm{k}_{13}$ (gain coefficient of the process of the DPS development) for the sinusoidal input function for 14 inputs and one output $y_{1}$, axis $y$-value of state variable $x_{1}$, axis $x$-periods of development (long time $\theta$ )

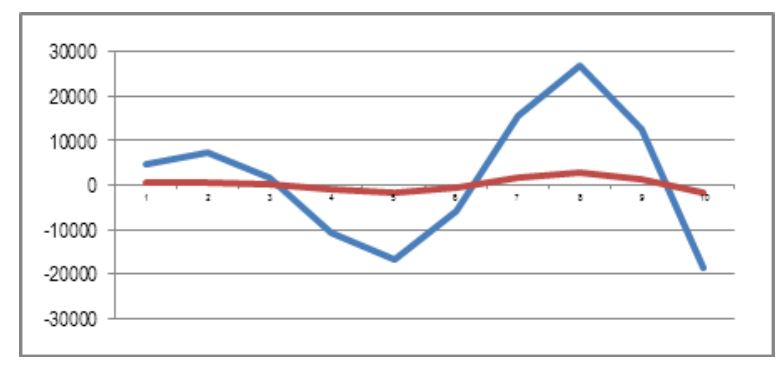

Fig. 6. Courses of the state variable $x_{1}$ (electrical power that can be produced during a year) relative to $\mathrm{k}_{11}, \mathrm{k}_{12}$ and $\mathrm{k}_{13}$ (gain coefficient of the process of the DPS development) for the sinusoidal input function for 14 inputs and one output $y_{1}$ during 10 periods of the DPS development, axis $y$-value of state variable $x_{1}$, axis $x$-periods of development (long time $\theta$ )

\section{Conclusion}

Using basic theory of control and identification systems, and the theory of systems development has enabled the generation of NPS development models in the form of a matrix th and in the state space (ss). As a result of solving the system of equations of the state variables with the use m-file in MATLAB give three state variables. On the basis of the solution obtained equations of state obtained in Simulink system response NPS (output variable $y_{1}$ ) force 
a type: $\operatorname{step} 1(\theta)$, the pulse $\operatorname{Dirac} \delta(\theta)$ and function $\sin (\theta)$, which are interpreted in terms of control theory and systems development. An attempt was made to design the system corrects the functioning model of development NPS. It turned out that the state observer can be designed for consideration of system development EE described state-space equations (9) which has a new matrix prior FR matrix input matrix $\mathbf{B}$ and $\mathbf{C}$ and $\mathbf{D}$. We examined the behavior of the model in terms of deserted factories to give a number of interesting research results. In further studies can take advantage of a vast amount of applications of artificial intelligence methods for the design and operation of NPS, including the method of evolution and artificial neural networks for the development of NPS in terms of control theory $[1,16,19]$, smart grid $[4,6,17]$, reliability systems $[11]$ and factories deserted $[3,6,16]$.

\section{References}

[1] Bolkowska B., Power system planning in terms of control theory, Archives of Energetic 4 (1974) (in Polish).

[2] Tadeusiewicz R., Study the properties of systems of cooperating with stochastically independent variable environment, Progress in Cybernetics 4 (1976) (in Polish).

[3] Tchórzewski J., Development of the electrical power system from the point of view of unmanned factories, Computer Applications in Electrical Engineering 12 (2014).

[4] Ekanayake J., Liyanage K., Wu J., and others, Smart Grid. Technology and Applications, A John Wiley \& Sons, Ltd, Publications, United Kongdom (2012).

[5] Kaczorek T., Dzieliński A., Dąbrowski W., Łopatka R., Fundamentals of control theory, WNT. Warsaw (2005) (in Polish).

[6] Kowalska-Puzalska A., The concept of smart grid opportunity for the development of distributed generation, Prace Naukowe IM, NiPE PWr 65, Studia i Materiały 31 (2011) (in Polish).

[7] Kocot H., Analysis and synthesis of the development of the power system using marginal cost, Monografie, Wyd. PŚ, Gliwice (2012) (in Polish).

[8] Malko J., Smart grid as a factor shaping the electricity sector, PTPiREE, Zaawansowane systemy pomiarowe - smart mattering w elektroenergetyce i gazownictwie, Warszawa (2010) (in Polish).

[9] Mielczarski W. [ed.], The development of power systems. Selected aspects, IE PŁ. Łódź (2004) (in Polish).

[10] Osowski S., Modeling and simulation of dynamic systems and processes, OW PW, Warszawa (2007) (in Polish).

[11] Paska J., Reliability of power systems, OW PW, Warsaw (2005) (in Polish).

[12] Popławski T., Theory and practice of development planning and operation of power systems. Selected aspects, P. Cz., Częstochowa (2013) (in Polish).

[13] Raczkowski K., Economic security. Challenges for the management of the State, Wolters Kluwer, Warszawa (2012).

[14] Rebizant W., Intelligent methods in automatic protection devices, PN IE Seria: Monografie 29(93), OW PWr., Wrocław (2004).

[15] Polish Electric Power Statistics, ARE. Warszawa (1947-2007) (in Polish).

[16] Tchórzewski J., The development of the power system in terms of control and systems theory, OW PWr., Wrocław (2013) (in Polish).

[17] Wasiak I., Electrical power at a glance. Transmission and distribution of electricity, Wyd. PŁ., Łódź (2010) (in Polish).

[18] Zajczyk R., Mathematical models for the study of the power system electromechanical transients and regulatory processes, Wyd. PG, Gdańsk (2003) (in Polish).

[19] Zimmer A., Englot A., Identification of objects and signals. Theory and practice for MATLAB users, Politechnika Krakowska, Kraków (2005) (in Polish). 